\title{
IMPACT OF THE FEED-IN GENERATION IN THE PRICES OF THE IBERIAN ELECTRICITY MARKET IN 2013
}

\author{
Pedro Gonçalves ${ }^{1}$, João Tomé Saraiva ${ }^{1,2, *}$ \\ ${ }^{1}$ Faculdade de Engenharia da Universidade do Porto, Rua Dr. Roberto Frias, 4200465 Porto, Portugal \\ ${ }^{2}$ INESC TEC, Rua Dr. Roberto Frias, 4200465 Porto, Portugal \\ *jsaraiva@fe.up.pt
}

Keywords: Electricity markets, Iberian Electricity Market, feed-in generation, prices

\begin{abstract}
Power industry has been deeply restructured in recent decades. Along this period vertically integrated structures evolved to more disaggregated models in which some activities are now provided under competition as generation and retailing while some others are provided under regulated monopolies as network transmission and distribution. Simultaneously, most countries started to encourage the use of renewable sources, namely to cope with environmental issues and to enlarge the energy independency. Having in mind these ideas and given the development of the Iberian Electricity Market and the increase of the installed capacity in units paid by feed-in tariffs, it becomes important to estimate the impact of this feed-in generation in the market prices. This paper describes the approach that was developed to estimate this impact and the implemented software application. This application was then used to evaluate the impact on prices on all trading hours of 2013 of the Portuguese photovoltaic generation, the Portuguese wind generation, all the Portuguese feed-in generation and also all the Iberian feed-in generation.
\end{abstract}

\section{Introduction}

The increasing share of feed-in generation in the generation mix of Portugal and Spain makes it important to evaluate the impact of the presence of this type of generation in the prices of the Iberian Electricity Market, MIBEL. In Portugal, Special Regime Generation, SRG, includes wind, photovoltaic, cogeneration, biomass as well as small hydros till 10 MVA of installed capacity. SRG differs from Normal Regime Generation, NRG, in what concerns the remuneration and the dispatch. SRG is paid by feed-in tariffs that depend on the technologies in the sense that these tariffs include a so called environmental term that is technology dependent. Differently, NRG establishes bilateral contracts or bids on MIBEL day-ahead market being paid at the pool market prices. NRG includes all more traditional power stations as coal and natural gas stations as well as large hydros. Apart from the remuneration, there is another important distinction between SRG and NRG. In fact, the legal status of SRG ensures that all the generated electricity is accepted in the networks while NRG bids on the pool market and so it may eventually not operate.

Although not subjected to a market bid based dispatch, the forecasted SRG generation is taken into account by the Market Operator when building the aggregated selling curves for the next day. In fact, SRG generation supplies demand and it is obvious that more SRG generation means that less demand is available to be supplied by NRG. In order to consider the SRG in the market curves, for each hour of the next day a zero price segment is included in the aggregated selling curve thus enforcing its dispatch [1]. On the other hand, including these zero price segments corresponds to shift to the right the selling curve that includes the bids from NRG thus contributing to lower the final market price.

The impact of SRG in the pool prices was estimated considering several scenarios in which we assume that zero price segments associated to specific SRG technologies are eliminated from the clearing process, that is, from the market curves provided by the Market Operator. After doing this, the market price for each hour is computed again assuming that the demand curve remained unchanged. In order to automate these calculations it was developed an application in VBA (Visual Basic for Applications) that uses the data about the buying and selling bids taken from the Iberian Market Operator webpage, builds the market curves, eliminates the SRG selected by the user and recalculates the market price for the period under analysis. This application was used to estimate the impact of SRG on the hourly prices along 2013 considering four scenarios: without Portuguese photovoltaic generation, without Portuguese wind generation, without all Portuguese SRG generation and without all Portuguese and Spanish SRG. This research was developed in the scope of the MSc Thesis prepared by the first author and submitted and approved at the Faculdade de Engenharia da Universidade do Porto by March 2015 [2].

According to these ideas, this paper is structured as follows. After this Introduction, Section 2 provides an overview on the trading platforms of MIBEL as well as on the Portuguese generation system and on the evolution of market prices in recent years, Section 3 details the algorithm that was implemented to estimate 
the mentioned impact of different SRG technologies on the market prices and Section 4 presents the results that were obtained for a particular day of 2013, for several months of 2013 as well as for the entire year. Finally, Section 5 draws the most relevant conclusions.

\section{Iberian Electricity Market - MIBEL}

The restructuring of electricity industry in European countries originated the development of several regional markets. In this scope, the Iberian Electricity Market was created in 2007 involving Portugal and Spain and it includes two trading operators - the OMIE corresponding to an entity that is physically located in Spain and that manages the day ahead and the intraday markets and the OMIP, physically located in Portugal and in charge of longer term trades and financial mechanisms [3].

The daily market operates in terms of a symmetric and volunteer day-ahead mechanism that admits both selling and buying bids. The trading period is 1 hour and selling entities can submit simple bids in terms of pairs (available quantity; minimum selling price) as well as complexity conditions, namely increasing and decreasing ramps and a minimum revenue to be obtained along the trading day. The minimum selling price should be non negative and the maximum buying price is limited to $180,00 € / \mathrm{MWh}$. For each trading hour of the next day, the market operator builds the aggregated selling and buying curves and obtains the cleared quantity and the market price in the intersection of these curves. Then, it checks whether complexity conditions are valid and if not it iterates the procedure introducing changes in the initial schedule $[4,5]$. In general, this corresponds to eliminate selling bids associated with violated constraints, as for instance the minimum revenue requirement. This elimination means that cheap initially cleared bids are not considered in the next iteration and so the remaining aggregated curve is shifted to the left side determining a progressive price increase as the clearing procedure develops.

Apart from the day ahead trading platform, the market operator also manages an intraday market that currently has 6 sessions as a way to adjust the selling or buying positions closer to the operation hour.

For the last twenty years several countries adopted policies to induce investments in renewable generation (namely wind parks, small hydros's, photovoltaic's and biomass units) and in non-renewable units as cogeneration as a way to use more intensively endogenous resources and to contribute to increase the energy independency. Among the most successful countries towards this objective, Portugal and Spain increased this type of capacity to $6.500 \mathrm{MW}$ out of 18.000 MW in Portugal and to $35.000 \mathrm{MW}$ out of 102.000 MW in Spain. Regarding the generation from these sources, in Portugal it corresponded to a value close to $40 \%$ in 2012 (from which $25 \%$ from wind parks) while in Spain it reached $38 \%$ of the total (from which $20 \%$ from wind parks). It is important to notice that these values do not include the generation from large hydro stations. If these stations are considered, then in $201360 \%$ of the Portuguese demand was supplied by renewables, $20 \%$ by coal stations and $15 \%$ by CCGT stations while the remaining $5 \%$ were imports.

As its legal designation suggests, the huge capacity increase of Special Regime Generation, SRG, is certainly due to the particular rules that were adopted to pay the generation from these units. In Portugal the first legislation to frame the operation of these units was passed in 1988 and it currently corresponds to a feed-in mechanism in which the final price depends on avoided investment and operation costs and on an environmental technology dependent term. The avoided investment and operation costs are obtained regarding the traditional thermal units that are not necessary to build and operate, CCGT in this case. Finally, the environmental term prizes cleaner or still less mature technologies. As a result, the average price paid to wind parks is currently close to $80 € / \mathrm{MWh}$ and is above 200 $€ / \mathrm{MWh}$ to small photovoltaic units. In Spain SRG generation can opt between a regulated feed-in tariff or receiving the market price plus a prize that corresponds to a percentage of a regulated reference value.

The impact of such large volumes of SRG generation is very important, namely considering that the average price in the day ahead market common to Portugal and Spain is typically below the feed in tariff levels for the different SRG technologies, namely for wind. For example, Figure 1 shows the monthly evolution of the average market price in Portugal and in Spain in 2008.

In 2008, the average market price was $69,98 € / \mathrm{MWh}$ in Portugal and $64,43 € / \mathrm{MWh}$ in Spain, suggesting that market splitting was frequent and that congestion occurred in the direction from Spain to Portugal.

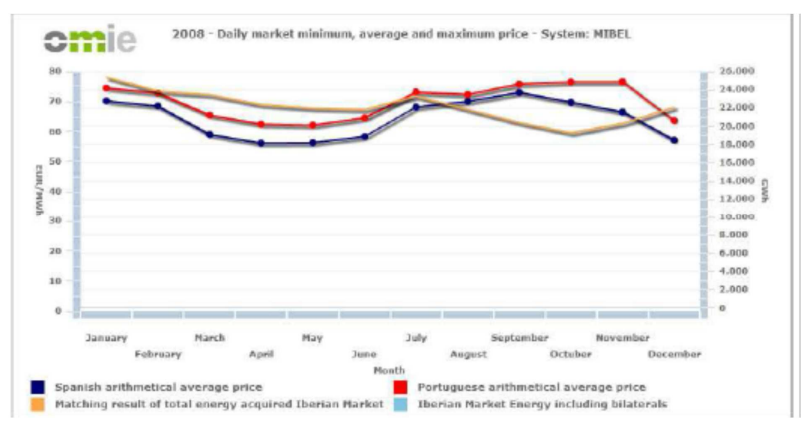

Fig. 1. Monthly results of the Iberian Electricity Market in 2008: dark blue - average price in Spain ( $€ / \mathrm{MWh})$; red - average price in Portugal ( $€ / \mathrm{MWh})$; light blue traded energy (GWh) (source OMIE web page).

In 2013 (see Figure 2), the average market prices declined to $43,37 € / \mathrm{MWh}$ in Portugal and to 44,26 $€ / \mathrm{MWh}$ in Spain, that is $38 \%$ and $31 \%$ below the values of 2008 in the two countries. It is important to notice that in 2013 the two average prices are much closer 
compared to 2008 suggesting that congestion was rare (in fact it occurred in less of $15 \%$ of the hours in 2013) and that when market splitting was activated it was applied more frequently in the direction from Portugal to Spain.

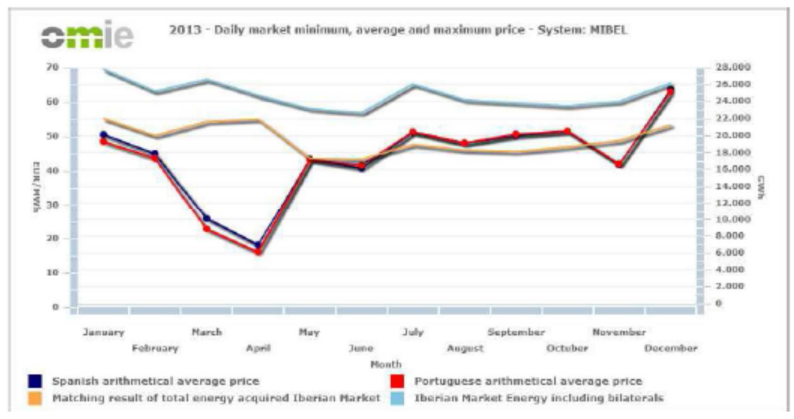

Fig. 2. Monthly results of the Iberian Electricity Market in 2013: dark blue - average price in Spain (€/MWh); red - average price in Portugal ( $€ / \mathrm{MWh})$; orange traded energy in MIBEL (GWh); light blue - trade energy plus bilateral contracts (GWh) (source OMIE web page).

Given the level of SRG feed in generation, it is clear that the presence of this generation has a strong impact on the final prices. Although not being paid the hourly market price, SRG estimates are considered in the market clearing of each hour of the next day because they contribute to balance the supply and the demand. In practice, zero price segments are added to the selling bid curve corresponding to the estimated hourly SRG generation. As a result, when SRG generation is large the market prices decline and less traditional thermal generators are cleared. This ultimately means that the total number of hours these thermal generators operate has been declining thus reducing their income.

\section{Estimation of the Impact of SRG}

As mentioned before, SRG generation must be considered when building the aggregated hourly market curves in order to balance the global demand and generation. This is done including in the selling aggregated curve zero price segments with quantities based on the estimates for each hour of the next day for the generation of each SRG technology. It is therefore clear that in periods in which SRG generation is large the selling bid curve from other generation agents and technologies shifts to the right side and so the market price gets reduced. On the contrary, if for instance wind generation (the most relevant SRG) is small then the corresponding zero price segment is less extended, the electricity price increases and more thermal selling bids are accepted. If a very windy period occurs together with large hydro inflows (as it is typical in November till March/April) then market prices have sharp declines and can continuously be at $0,00 € / \mathrm{MWh}$ for several hours as it occurred in March and April 2013. As an example, in the $9^{\text {th }}$ of April 2013 the market prices were less than $1,00 € / \mathrm{MWh}$ for 19 hours of that day, and during 13 of which the price was $0,00 € / \mathrm{MWh}$.

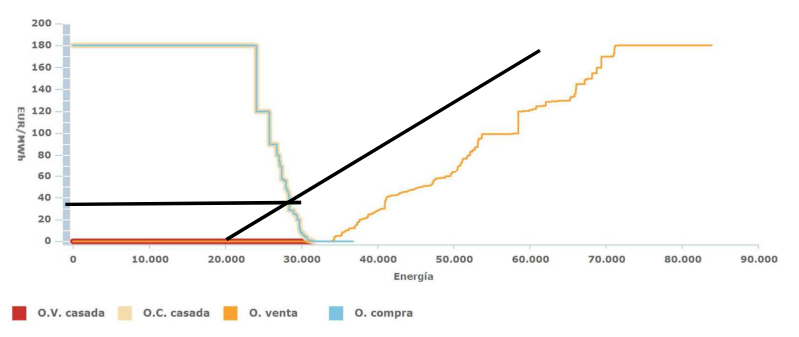

Fig. 3. Aggregated selling and buying curves for the Iberian electricity market for hour 1 of March 12, 2013 (source OMIE web page).

Figure 3 illustrates this impact showing the selling and buying curves for hour 1 of March 12 2013. At this hour the market price was $0,00 € / \mathrm{MWh}$ as a result of the intersection of the buying (blue) and selling (red) curves. The 0,00€/MWh selling bid segment amounts to $32.000 \mathrm{MWh}$ resulting from about 7.000 MWh from nuclear stations, $13.000 \mathrm{MWh}$ from hydro stations and 12.000 MWh from wind parks. If this $12.000 \mathrm{MWh}$ segment was not present, then the selling curve would be shifted to the left as illustrated by the black line and so the market price would increase from 0,00 to about $38,00 € / \mathrm{MWh}$. This illustrates the impact of the SRG subsidized generation in the market price and in the schedule. Apart from the reduction of the market price, considering the SRG 0,0 price segment in the selling curve reduces the number of accepted bids from thermal generators. Globally, the income obtained by thermal stations is reduced not only because the market price gets reduced but also because the number of hours they are dispatched also gets smaller. As a consequence, the number of operation hours of combined cycle power stations (the marginal technology in most periods) is getting more and more reduced in recent years and only some coal stations are dispatched.

Using this reasoning, we analysed the impact of SRG generation on the market prices during the entire year of 2013 considering the following four cases:
$\mathrm{i}=1$ Clearing process not considering the wind generation located in Portugal;
$\mathrm{i}=2$ Clearing process not considering the photovoltaic generation located in Portugal;
$\mathrm{i}=3$ Clearing process not considering all the SRG generation located in Portugal. This includes not only wind and photovoltaic, but also small hydros, cogeneration, biomass and residue power stations;
$\mathrm{i}=4$ Clearing process not considering all the SRG generation from both Portugal and Spain.

In order to estimate the impact on the prices it was necessary to know the generation values for each of these four cases for each hour of 2013. These hourly values discriminated by SRG technology were provided by EDP Gestão da Produção SA to whom the authors are thankful. 
Then, for a particular case $\mathrm{i}=1$ to 4 and for a particular hour k of 2013 the next steps were followed:

1. in the first place, the data regarding the submitted and the accepted selling and buying bids was downloaded from the web page of the Iberian Market Operator (www.omie.es). Let us also assume that PSRG,ik is the SRG generation associated with case i for hour k. For instance, for $\mathrm{i}=1$ it corresponds to the first case, not considering the generated power from wind parks located in Portugal in hour k;

2. secondly, the total amount of power bid at 0,00 $€ / \mathrm{MWh}$ at hour $\mathrm{k}$ was obtained adding all the power from zero price bids. Let us denote this 0,00 price power quantity as $\mathrm{P}_{0,00, \text { Totalk }}$;

3. then, the selling bid of $P_{0,00, \text { Totalk }}$ at 0,00 $€ / M W h$ was eliminated from that data downloaded in 1. and substituted by a bid at $0,00 € / M W h$ with power given by $\mathrm{P}_{0,00, \text { Totalk }}-\mathrm{P}_{\mathrm{SRG}, \mathrm{ik}}$. When building the new aggregated selling curve this means that the original selling curve is shifted to the left side by PSRG,ik;

4. using the downloaded data and having in mind the modification introduced in step 3 on the selling bids at $0,00 € / \mathrm{MWh}$, it is solved the linear optimization problem given by (1-4) in order to maximize the Social Welfare Function, SWF, as defined in [6]. This problem was solved using the linprog function of the Optimization Toolbox of MatLab®.

$$
\begin{array}{ll}
\max & \mathrm{Z}=\sum_{\mathrm{j}=1}^{\mathrm{N}_{\mathrm{D}}} \mathrm{Cd}_{\mathrm{j}} \cdot \mathrm{Pd}_{\mathrm{j}}-\sum_{\mathrm{i}=1}^{\mathrm{N}_{\mathrm{G}} \mathrm{Cg}_{\mathrm{i}} \cdot \mathrm{Pg}_{\mathrm{i}}} \\
\text { subj to } & 0 \leq \mathrm{Pd}_{\mathrm{j}} \leq \mathrm{Pd}_{\mathrm{j}} \text { máx } \\
& 0 \leq \mathrm{Pg}_{\mathrm{i}} \leq \mathrm{Pg}_{\mathrm{i}} \text { máx } \\
& \sum_{\mathrm{j}=1}^{\mathrm{N}_{\mathrm{D}}} \mathrm{Pd}_{\mathrm{j}}=\sum_{\mathrm{i}=1}^{\mathrm{N}_{\mathrm{G}} \mathrm{Pg}_{\mathrm{i}}}
\end{array}
$$

In this formulation $\mathrm{Cd}_{\mathrm{j}}$ and $\mathrm{Cg}_{\mathrm{i}}$ are the buying and selling prices, $\mathrm{Pd}_{\mathrm{j}}^{\max }$ and $\mathrm{Pg}_{\mathrm{i}}^{\max }$ are the maximum demand and generation bid quantities, $\mathrm{Pd}_{\mathrm{j}}$ and $\mathrm{Pg}_{\mathrm{i}}$ are the demand and generation at the final solution and $\mathrm{N}_{\mathrm{D}}$ and $\mathrm{N}_{\mathrm{G}}$ are the number of buying and selling bids. The objective function $\mathrm{Z}$ in (1) is subjected to limits on the demand (2) and on the generation (3) bids and to the demand / supply balance equation (4). In this simulation we did not consider the selling bids that were removed by the Market Operator along the iterative clearing process to check the complexity constraints, as described in the second paragraph of Section 2;
5. once the above problem is solved for case $\mathrm{i}$ and hour $\mathrm{k}$, the dual variable of the power balance equation (4) corresponds to the new market clearing price since it corresponds to the impact on the objective function from changing the demand by 1 unit. In a graphical way, this corresponds to draw the buying and selling curves and obtain the intersection point to define the cleared quantity and the market price. However, for real sized problems, the market price can be obtained using the dual variable of the generation/demand balance equation.

In order to enable analyzing a full year in an automated way it was implemented an application in VBA (Visual Basic for Applications) that allows the user to select the period under analysis and the simulation to perform in terms of the SRG technology to analyse. The application automatically assesses the Market Operator web page and downloads the market data required for the analysis. Then, all data concerning the SRG generation on the period under analysis is also automatically obtained from the file provided by EDP Gestão da Produção, SA. Once the data download is completed, the application begins to estimate the new market price for each hour for the selected case, by ignoring the correspondent value of SRG generation. Given that $0,00 € / \mathrm{MWh}$ bids were eliminated, the clearing process requires accepting selling bids that were not initially cleared so that the new market price corresponds once again to the intersection point of the aggregated offer and demand curves. As soon as the application finishes running, all intermediate results are made available to the user, including all values and graphs for every hour. The average prices are also calculated for the period under analysis, allowing a global view on the estimated results.

\section{Results obtained for 2013}

In this Section we will detail the results that were obtained applying the approach detailed in Section 3 to the year of 2013. In the first place, we will detail the results obtained for hour 11 of the $9^{\text {th }}$ of April 2013 on which the original market price was $1,00 € / \mathrm{MWh}$. Then, aggregated results will be presented for typical winter and summer months (January and July) and also for April because this is typically a very windy month and in 2013 it was also a very rainy period. Finally, Section 4.5 presents aggregated average results for 2013 .

\subsection{Results for the hour 11 of $9^{\text {th }}$ of April 2013}

The original market price obtained by the market operator for the hour 11 of $9^{\text {th }}$ of April 2013 was 1,00 $€ / \mathrm{MWh}$. Then, Table I presents the results that were obtained for the four analysed cases (without Portuguese wind generation, without Portuguese PV generation, without all the Portuguese SRG generation and without all the Portuguese and Spanish SRG generation). It should be noticed that when eliminating the Portuguese PV generation, case $\mathrm{i}=2$, the market price remained 
unchanged given the very reduced Portuguese PV generation at that hour (33,75 MWh). Not considering all the Portuguese SRG generation lead to a price increase of $11,00 € / \mathrm{MWh}$ (from 1,00 to $12,00 € / \mathrm{MWh}$ ) and as expected, the largest impact occurs when all Portuguese and Spanish SRG generation is not considered. In this case, the market price increases from 1,00 to 60,06 $€ / \mathrm{MWh}$.

Table 1. Real and estimated prices (€/MWh) for hour 11 of the $9^{\text {th }}$ of April 2013

\begin{tabular}{ccccc}
\hline \hline $\begin{array}{c}\text { hour } \\
11\end{array}$ & $\begin{array}{c}\text { without } \\
\text { Port. } \\
\text { wind }\end{array}$ & $\begin{array}{c}\text { without } \\
\text { Port. } \\
\text { PV }\end{array}$ & $\begin{array}{c}\text { without } \\
\text { all Port. } \\
\text { SRG }\end{array}$ & $\begin{array}{c}\text { without } \\
\text { all MIBEL } \\
\text { SRG }\end{array}$ \\
\hline \hline price & price & price & price & price \\
\hline 1,00 & 10,00 & 1,00 & 12,00 & 60,06 \\
\hline
\end{tabular}

In a graphical way, the evaluation of the impact of SRG on the market price is illustrated in Figure 4. The red curve represents the aggregated buying curve and the blue curve is the aggregated buying curve shifted to the left side by an ammount that corresponds to the SRG generation associated with the case $i=1 . .4$ under analysis. In this case, this Figure is associated with case $\mathrm{i}=4$ and so the original selling curve was shifted to the left by 22.983 MWh corresponding to all the Portuguese and Spanish SRG generation at this hour. Therefore, the market price increased from 1,00 $€ / \mathrm{MWh}$ to 60,06 $€ / M W h$ as indicated before.

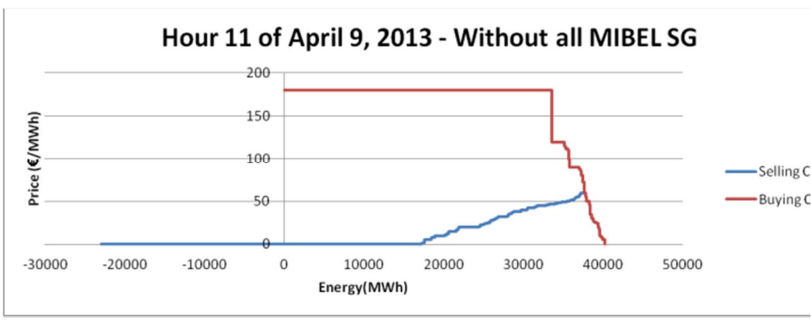

Fig. 4. Aggregated selling and buying curves for the case $i=4$ for hour 11 of April 9, 2013. [2]

\subsection{Results for January 2013}

Table 2 presents the monthly average prices obtained for January 2013 . The real average price was $48,34 € / \mathrm{MWh}$ and this value remained almost unchanged when not considering the Portuguese PV generation, not only due to the reduced installed capacity (about $250 \mathrm{MW}$, less than $1,5 \%$ of the installed capacity in the country) but also because of the reduced number of insulation hours in January. The larger impact occurred again for case $i=4$ when not considering all the Portuguese and Spanish SRG generation given that the average market price rose from $48,34 € / \mathrm{MWh}$ to $95,85 € / \mathrm{MWh}$, which almost corresponds to its duplication.
Table 2 Real and estimated prices ( $€ / M W h)$ for January 2013.

\begin{tabular}{ccccc}
\hline \hline $\begin{array}{c}\text { January } \\
2013\end{array}$ & $\begin{array}{c}\text { without } \\
\text { Port. } \\
\text { wind }\end{array}$ & $\begin{array}{c}\text { without } \\
\text { Port. } \\
\text { PV }\end{array}$ & $\begin{array}{c}\text { without } \\
\text { all Port. } \\
\text { SRG }\end{array}$ & $\begin{array}{c}\text { without } \\
\text { all MIBEL } \\
\text { SRG }\end{array}$ \\
\hline \hline price & price & price & price & price \\
\hline 48,34 & 56,50 & 48,39 & 64,10 & 95,85 \\
\hline
\end{tabular}

\section{$4.3 \quad$ Results for April 2013}

In April 2013 the average market price was 16,01 $€ / M W h$. This value almost doubled not considering all the Portuguese SRG generation and more than triples not considering all the Portuguese and Spanish SRG. Table 3 presents the average prices that were obtained for this month. It should be noticed that the average market price in April reduces regarding the value in January (reduction from 48,34 to $16,01 € / \mathrm{MWh}$ ) confirming the larger presence of wind SRG generation modeled by the zero price segments in the clearing process, and also the intensive use of hydro stations.

Table 3 Real and estimated prices (€/MWh) for April 2013.

\begin{tabular}{ccccc}
\hline \hline $\begin{array}{c}\text { April } \\
2013\end{array}$ & $\begin{array}{c}\text { without } \\
\text { Port. } \\
\text { wind }\end{array}$ & $\begin{array}{c}\text { without } \\
\text { Port. } \\
\text { PV }\end{array}$ & $\begin{array}{c}\text { without } \\
\text { all Port. } \\
\text { SRG }\end{array}$ & $\begin{array}{c}\text { without } \\
\text { all MIBEL } \\
\text { SRG }\end{array}$ \\
\hline \hline price & price & price & price & Price \\
\hline 16,01 & 22,00 & 16,16 & 29,26 & 52,09 \\
\hline
\end{tabular}

\subsection{Results for July 2013}

Table 4 presents the results for July 2013. The impact of not considering the Portuguese wind generation is now much smaller because July is typically not a windy month. Although the number of insulation hours is much larger in July, the impact of the Portuguese PV generation remains very reduced because in 2013 the PV installed capacity was still reduced.

Table 4 Real and estimated prices ( $€ / \mathrm{MWh}$ ) for July 2013.

\begin{tabular}{ccccc}
\hline \hline $\begin{array}{c}\text { July } \\
2013\end{array}$ & $\begin{array}{c}\text { without } \\
\text { Port. } \\
\text { wind }\end{array}$ & $\begin{array}{c}\text { without } \\
\text { Port. } \\
\text { PV }\end{array}$ & $\begin{array}{c}\text { without } \\
\text { all Port. } \\
\text { SRG }\end{array}$ & $\begin{array}{c}\text { without } \\
\text { all MIBEL } \\
\text { SRG }\end{array}$ \\
\hline \hline price & price & price & price & price \\
\hline 51,30 & 53,12 & 51,41 & 55,55 & 79,31 \\
\hline
\end{tabular}

\subsection{Average results for 2013}

Once all the scenarios were analysed for every hour of 2013, it was possible to compute the average yearly market prices as detailed in Table 5. 
Table 5 Real and estimated average prices ( $€ / \mathrm{MWh}$ ) for 2013.

\begin{tabular}{ccccc}
\hline \hline \multirow{2}{*}{2013} & $\begin{array}{c}\text { without } \\
\text { Port. } \\
\text { wind }\end{array}$ & $\begin{array}{c}\text { without } \\
\text { Port. } \\
\text { PV }\end{array}$ & $\begin{array}{c}\text { without } \\
\text { all Port. } \\
\text { SRG }\end{array}$ & $\begin{array}{c}\text { without } \\
\text { all MIBEL } \\
\text { SRG }\end{array}$ \\
\hline \hline price & price & price & price & price \\
\hline \hline 43,37 & 49,13 & 43,53 & 54,11 & 82,63 \\
\hline
\end{tabular}

In the first place, the average market price of MIBEL in 2013 was 43,37 €/MWh. This value would increase by $5,76 € / \mathrm{MWh}$ not considering the Portuguese wind generation, by $0,16 € / \mathrm{MWh}$ not considering the Portuguese photovoltaic generation, by $10,74 € / \mathrm{MWh}$ without all the Portuguese SRG generation and finally by $39,26 \in / \mathrm{MWh}$ if all the SRG generation both in Portugal and Spain was ignored. Regarding these results it should be noticed that Portugal had in 2013 a wind installed capacity of $4.730 \mathrm{MW}$ which corresponds to the largest value per technology. If this generation was ignored, the average market prices would rise by $13,25 \%$. However, if no Portuguese SRG was considered, then the price would increase by $24,76 \%$. Given the small impact of photovoltaic generation, we can conclude that the difference is mainly due to small hydro's, cogeneration and units using residues, although their installed capacity is only $1.900 \mathrm{MW}$. This obviously suggests that small hydro's, cogeneration and residue units have a much larger number of operation hours when compared to the wind installations. Therefore, although having 2,5 times less installed capacity regarding wind parks, the impact of not considering these units is almost the same as the impact of wind generation

\section{Conclusions}

This paper reports the results regarding the estimation of the impact of the feed in generation in the prices of the day ahead market common to Portugal and Spain. This analysis is relevant given the large installed capacity benefiting from feed in rules. These units are considered in the market clearing process by including $0,0 € / \mathrm{MWh}$ price segments in the aggregated selling curve thus shifting to the right side the bids from the remaining generation agents. As a whole, we estimated that not considering SRG generation from both Portugal and Spain would increase the average price in 2013 from $43,37 € / \mathrm{MWh}$ to $82,63 € / \mathrm{MWh}$. The presence of SRG reduces the market price and the number of operation hours of units using traditional thermal technologies strongly contributing to reduce the revenues of these units. This impact should be carefully evaluated to check if in the long term this does not risk the security of supply given the volatile nature of the resources used by several SRG units.

\section{Acknowledgements}

The first author wishes to thank EDP Gestão da Produção SA, namely to Eng. José Carlos Sousa for all the insights, discussions and data regarding SRG generation that was provided.

\section{References}

[1] "Information on the Special Regime Generation", ERSE, Portuguese Regulatory Agency for the Energy Services, http://www.erse.pt/pt/desempenhoambiental/prodregesp /Documents/Info_mensal/SIPREinfoJun14.pdf, accessed 08/12/2014.

[2] Gonçalves, P. P., "Evaluation of the Impact Of the Special Regime Generation in the Market Prices of MIBEL" (in Portuguese), MSc. Thesis, Engineering Faculty of University of Porto, Portugal, March 2015.

[3] "OMIE and OMIP" (in Portuguese), http://www.omip.pt/OMIP/OMIE/tabid/71/language/ptPT/Default.aspx, accessed 07/12/204.

[4] "Contracting Energy in MIBEL" (in Portuguese), ERSE, Portuguese Regulatory Agency for the Energy Services, http://www.erse.pt/pt/supervisaodemercados/mercadode electricidade/contratacao/Paginas/default.aspx, accessed 06/12/2014.

[5] "The MIBEL Daily Market" (in Portuguese), ERSE, Portuguese Regulatory Agency for the Energy Services, http://www.erse.pt/pt/supervisaodemercados/m ercadodeelectricidade/mercadodiario/Paginas/default.as px, accessed 07/12/2014.

[6] Stoft, S., "Power System Economics", IEEE/Wiley, ISBN 0-471-15040-1, February 2002. 